\title{
Comparative In Vitro Biological Toxicity of Four Kinds of Air Pollution Particles
}

\author{
Han-Jae Shin ${ }^{1}$, Hyun Gi Cho ${ }^{2}$, Chang Kyun Park², Ki Hong Park and Heung Bin Lim² \\ ${ }^{1} K T \& G$ Research Institute, Daejon, Korea \\ ${ }^{2}$ College of Agriculture, Life \& Environment Sciences, Chungbuk National University, Cheongju, Korea \\ ${ }^{3}$ School of Environmental Science and Engineering, GIST, Gwangju, Korea
}

\begin{abstract}
Accumulating epidemiological evidence indicates that exposure to fine air pollution particles (APPs) is associated with a variety of adverse health effects. However, the exact physiochemical properties and biological toxicities of fine APPs are still not well characterized. We collected four types of fine particle (FP) (diesel exhaust particles [DEPs], natural organic combustion [NOC] ash, synthetic organic combustion [SOC] ash, and yellow sand dust [YSD]) and investigated their physicochemical properties and in vitro biological toxicity. DEPs were almost entirely composed of ultrafine particles (UFPs), while the NOC, SOC, and YSD particles were a mixture of UFPs and FPs. The main elements in the DEPs, NOC ash, SOC ash, and YSD were black carbon, silicon, black carbon, and silicon, respectively. DEPs exhibited dose-dependent mutagenicity even at a low dose in Salmonella typhimurium TA 98 and 100 strains in an Ames test for genotoxicity. However, NOC, SOC, and YSD particles did not show any mutagenicity at high doses. The neutral red uptake assay to test cell viability revealed that DEPs showed dose-dependent potent cytotoxicity even at a low concentration. The toxicity of DEPs was relatively higher than that of NOC, SOC, and YSD particles. Therefore, these results indicate that among the four FPs, DEPs showed the highest in vitro biological toxicity. Additional comprehensive research studies such as chemical analysis and in vivo acute and chronic inhalation toxicity tests are necessary to determine and clarify the effects of this air contaminant on human health.
\end{abstract}

Key words: Air pollution particle, Physicochemical properties, Mutagenicity, Cytotoxicity

\section{INTRODUCTION}

The Organisation for Economic Co-operation and Development (OECD) indicated in their report, "The Economic Consequences of Outdoor Air Pollution", published on June 09,2016 , that there were approximately 3 million premature deaths related to outdoor air pollution worldwide in 2010 and projected that the incidence will be $6 \sim 9$ million in 2060. Particularly, in Korea, the number of deaths caused by outdoor air pollution per million was estimated to be 259

Correspondence to: Heung Bin Lim, College of Agriculture, Life \& Environment Sciences, Chungbuk National University, Cheongju, Chungbuk 28644, Korea

E-mail: heungbin@chungbuk.ac.kr

This is an Open-Access article distributed under the terms of the Creative Commons Attribution Non-Commercial License (http:// creativecommons.org/licenses/by-nc/3.0) which permits unrestricted non-commercial use, distribution, and reproduction in any medium, provided the original work is properly cited. in 2010 , but it is currently predicted to be 1,109 and furthermore, the incidence is increasing towards a potentially alarming world record for the nation.

Ultrafine particles (UFPs) of air pollutants, which are less than $2.5 \mu \mathrm{m}$ in diameter, effectively bypass the deposition process of the nasal and trachea bronchial mucus. This can result in a higher proportion of particles reaching the lower respiratory tract, which greatly affect the human body, including respiratory function (1). Although fine particle (FP)induced injuries and damages appear to occur to varying degrees, particle-mediated inflammation may likely be the predominant mechanism of respiratory tract injury and cardiovascular effects (2).

Gas phase and particulate matter emitted following incomplete combustion and burning of organic or inorganic matter worsen the air quality, have a deleterious effect on the respiratory system, and are commonly known to cause various respiratory diseases such as bronchitis, asthma, chronic obstructive pulmonary disorder (COPD), and lung cancer 
(3). Particulate matters composed of a diverse mixture of FPs and UFPs, containing metals, soot, tar, black carbon, and carbonaceous materials, have a relatively large surface area to absorb toxic materials (4). Following absorption, these materials can be subsequently delivered to the bronchus or germinal cells where they adhere to the lungs and induce mutagenicity and carcinogenesis (5).

Combustion-derived diesel engine exhaust from cars, trucks, buses, and recreational vehicles contains black carbon and hydrocarbons $\left(\mathrm{C}_{14}-\mathrm{C}_{35}\right)$, as well as heterocyclic polycyclic aromatic hydrocarbons (PAHs) and the derivatives of these substances. In addition, it contains acids, alcohols, esters, anhydrides, ketones, nitriles, quinones, sulfonates, organic halogens, inorganic sulfates and nitrates, and heavy metals (6), which are known to cause respiratory diseases such as inflammation, lung cancer, asthma, and allergies (7).

Natural organic combustion (NOC) smoke is emitted from forest fires and materials burnt to heat rooms and for cooking, including biomass fuels such as woods, pellets, and grain husks, which are time-honored traditional practices. The particle emissions from NOC are nano-sized and contain oxidation products such as metals, black carbon, PAHs, and heterocyclic compounds $(8,9)$. Synthetic organic combustion (SOC) smoke emitted from industrial waste incinerators also contain fly ashes, metals, halogenated PAHs, dioxins, and heterocyclic compounds (10). Yellow sand dust (YSD) contains particles that are mostly less than $5 \mu \mathrm{m}$ in diameter and consists of heavy metals, acidic substances, inorganic sulfates and nitrates, bacteria, and fungi (11).

Furthermore, the physical characteristics and chemical analysis of a large number of toxic components of air pollutants with potentially harmful health effects have been widely reported $(12,13)$. However, comparative in vivo and in vitro toxicological evaluations of these substances have rarely been conducted. Therefore, in this study, we collected FP samples of the air pollutants, diesel exhaust particles (DEPs), NOC ashes, SOC ashes, and YSD, to investigate their physical characteristics and perform chemical elemental analysis. Furthermore, we compared their in vitro toxicological activity, such as mutagenicity and cell toxicity, to evaluate their relative contribution to the associated human health effects.

\section{MATERIALS AND METHODS}

DEP collection. DEPs were provided by the National Institute for Environmental Studies in Tsukuba Science City, Japan. The DEP samples were collected using a glass filter in a constant-volume sampler system attached to the end of a dilution tunnel that was connected to a four-cylinder diesel engine (Isuzu Automobile Company, Tokyo, Japan), which operated at $1,500 \mathrm{rpm}$ under a 10 torque $(\mathrm{kg} \cdot \mathrm{m})$ load, as described previously (14). The particles were stored at $-70^{\circ} \mathrm{C}$ in a deep freezer until they were used for the experiments.

NOC ash collection. Dried rice husks were purchased at an animal feed store to prepare typical NOC ashes. Briefly, $1,115.33 \mathrm{~g}$ of dried rice husk was burned to ashes on the clean bottom of a clay fire pot, and the ashes were collected, strained using a standard testing sieve $(250 \mu \mathrm{m})$, and then stored at $-0^{\circ} \mathrm{C}$ in a deep freezer until used.

SOC ash collection. Synthetic organic matter (152.03 $\mathrm{g})$ consisting of $34.68 \mathrm{~g}$ black plastic bags, $34.68 \mathrm{~g}$ polyethylene terephthalate bottles and pastry wrappers, and Styrofoam were purchased at area markets and burned to ashes on the clean bottom of a clay fire pot. The ashes were collected, strained using a standard testing sieve $(250 \mu \mathrm{m})$, and stored at $-70^{\circ} \mathrm{C}$ in a deep freezer until used.

YSD collection. The YSD was collected from the rooftop of the S 21-1 building of Chungbuk National University. White plastic mats were laid on the rooftop in the early morning of the day on which a YSD storm warning was forecasted by the government. The YSD that sank naturally under the influence of gravity was collected and stored at $-70^{\circ} \mathrm{C}$ in a deep freezer until they were used for the experiments.

Physicochemical properties. The morphology and chemical composition of four FP types were determined using a high-resolution scanning electron microscopy (HR-SEM). The equipment used was the Quanta 200 FEG scanning electron microscope (FEI, Quanta FP2017/11), equipped with a chemical composition analysis system based on energy dispersive X-ray analysis (EDAX). The collected samples were mounted on an aluminum stud using carbon tape. The samples were then coated with gold using a sputter coating unit (MSD-1S, VD Co., Japan), with the vacuum set at $10 \mathrm{~Pa}$ for $10 \mathrm{sec}$. The acceleration potential used was $30 \mathrm{kV}$, and the images were captured at the desired magnification.

Bacteria and culture medium. The Salmonella typhimurium TA 98 and TA 100 tester strains used for evaluating frame-shift and base-pair substitution type mutations, respectively, were provided by the Korea Institute of Toxicology (KIT). The strains were grown with $2.5 \%$ nutrient liquid in a spinner flask at $37^{\circ} \mathrm{C}$ in a shaking incubator maintained at a speed of $80 \mathrm{rpm}$ for $10 \mathrm{hr}$. The minimal glucose agar plate was prepared by combining $1.5 \%$ Bacto agar, Vogel-Bonner medium E, and $2 \%$ glucose, while the top agar was prepared by the addition of $0.6 \%$ agar, $0.5 \%$ sodium chloride $(\mathrm{NaCl})$, and $0.05 \mathrm{mM}$ histidine-biotin. In addition, we analyzed the histidine requirement and conducted $u v r B$ mutation maintenance, R-factor maintenance, $r f a$ mutation, and spontaneous mutation tests. Both strains 
were used for these tests.

Mutagenicity assay. Mutagenicity was evaluated using the TA 98 and TA 100 S. typhimurium strains according to the method described by Maron and Ames (15). The test materials were incorporated in the plates, similar to the plate-incorporation method. The positive control groups contained $0.5 \mu \mathrm{g} / \mathrm{plate}$ of direct mutagen $4-\mathrm{NQO}, 1 \mu \mathrm{g} / \mathrm{plate}$ of sodium azide (SA), and $0.5 \mu \mathrm{g} /$ plate of indirect mutagen 2-AA. Dimethyl sulfoxide (DMSO) was also added to the agar plate as a negative control substance. In the test, we used $500 \mu \mathrm{L}$ of $0.2 \mathrm{M}$ sodium phosphate buffer ( $\mathrm{pH} 7.4$ ) instead of the S-9 mix for the group tested in the absence of hepatic metabolic activations; $500 \mu \mathrm{L} \mathrm{S}-9$ mix was included in the hepatic metabolic activation group, which required the indirect mutagen. Then, $100 \mu \mathrm{L}$ of the culture medium $\left(1-2 \times 10^{9}\right.$ cells $\left./ \mathrm{mL}\right)$ and the FPs were placed into a $5-\mathrm{mL}$ test tube. The mixture was mixed after replacing the cap tubes, and then it was poured into the culture medium and incubated for $48 \mathrm{hr}$ in an incubator at $37^{\circ} \mathrm{C}$. Finally, the number of revertant colonies on the plate was counted.

Determination of concentration. To set the maximum concentration used in this test, a $10 \mathrm{mg} / \mathrm{mL}$ stock solution of total particulate matter (TPM) from each of the extracted FPs was used. Finally, we set the maximum concentration at $1 \mathrm{mg} /$ plate. After the test, the reverse mutation colonies that exhibited a capacity correlation and reproducibility, as well as an increase two times that of the negative controls were considered to show positive mutations. If the background lawn was decreased compared with that of the negative controls, severe toxicity was confirmed. We established the optimal concentration based on these results.

Cytotoxicity (cell viability) test. The percentage cell viability was determined using the neutral red uptake assay to evaluate cytotoxicity according to the method of Ellen and James (16). CHO-K1 cells were seeded in 96-well plates at a density of $1.0 \times 10^{4}$ cell per well with $100 \mu \mathrm{L}$ of the culture medium. The 96-well plates were placed in a humidified atmosphere at $37^{\circ} \mathrm{C}\left(5 \% \mathrm{CO}_{2}\right.$ and $95 \%$ air $)$ for $24 \mathrm{hr}$. After aspirating the culture medium, $200 \mu \mathrm{L}$ of the diluted samples was dispensed into each well, followed by $24 \mathrm{hr}$ of incubation. At the designated times, diluted samples were replaced with $200 \mu \mathrm{L}$ of neutral red solution (50 $\mu \mathrm{g} / \mathrm{mL}$ in the culture medium without fetal bovine serum [FBS]) for $3 \mathrm{hr}$.

The neutral red solution was aspirated, $200 \mu \mathrm{L}$ of the wash-fix solution $(1 \%[\mathrm{v} / \mathrm{v}]$ formalin) was added to each well, and then the wash-fix solution was aspirated within $1 \mathrm{~min}$. Following this, $200 \mu \mathrm{L}$ of neutral red extract solution was added to each well, and the 96-well plate was placed on a microplate plate shaker for at least $10 \mathrm{~min}$. The optical density of each well was measured using a micro- plate reader (Bio-Tek, USA) at an absorption wavelength of $540 \mathrm{~nm}$. The dose-response curve was constructed using the test sample values expressed as a percentage of the control value (the absorbance of neutral red from UFP-treated cells was divided by corresponding control cell values). The halfmaximal effective concentration $\left(\mathrm{EC}_{50}\right)$ value (the dose that induced $50 \%$ inhibition of cell viability) was extrapolated from the dose-response curve.

Statistical analysis. The experimental data were presented as the mean \pm standard deviation (SD) of at least three replicates. A one-way analysis of variance (ANOVA) was conducted to compare the results of each UFP. The Student's $t$-test was used for the statistical analysis of the differences and $p \leq 0.05$ was considered statistically significant.

\section{RESULTS}

\section{Physicochemical properties.}

- DEP: The mean particle size of the DEP samples measured using an electron microscope was mostly $<4 \mu \mathrm{m}$ (Fig. 1). Furthermore, most DEPs were $<3 \mu \mathrm{m}$ in diameter, completely black, and spherical. These results are in accordance with the results of Sagai et al (14). Elemental analysis of the DEPs showed that they contained carbon at the highest level, followed by oxygen, zirconium, silicon, palladium, sulfur, silver, and calcium. The results reported by Surawski et al. (17) showed a particle size distribution that had a strong dependency on the biodiesel blend percentage. In addition, the median particle diameter decreased as the biodiesel blend percentage increased. We confirmed that the DEP samples were produced by incomplete oxidation when light oil was burned in the diesel engine in our experiments.

- NOC: The NOC particle size had a very wide range, from 4 to $10 \mu \mathrm{m}$ in diameter. The rice husks were easily burned in a fire pot without requiring any accelerant because they were dried sufficiently. Most of the NOC ash samples were nearly black and lineal. The following proportions of chemical elements were detected in the NOC samples, in descending order of atomic content: $66.52 \%$ silicon, $10.53 \%$ zirconium, $8.14 \%$ potassium, $3.87 \%$ chloride, $2.27 \%$ palladium, $2.22 \%$ sodium, $2.06 \%$ calcium, and $2.00 \%$ magnesium. The NOC process was likely complete since the carbon content was almost nonexistent in the ash samples. Faustini et al. (18) reported that NOC smoke generated by wildfire was associated with increased cardiovascular mortality in urban residents, and the particulate matter less than 10 microns in diameter (PM10) on smoky days has a greater effect on cardiovascular and respiratory mortality than it did on other days. Naeher et al. (19) also reported that NOC in wood-burning stoves and fireplaces as well as wildland and agricultural fires emitted significant quantities of known health-damaging pollutants, including several carcinogenic compounds. 
(A)
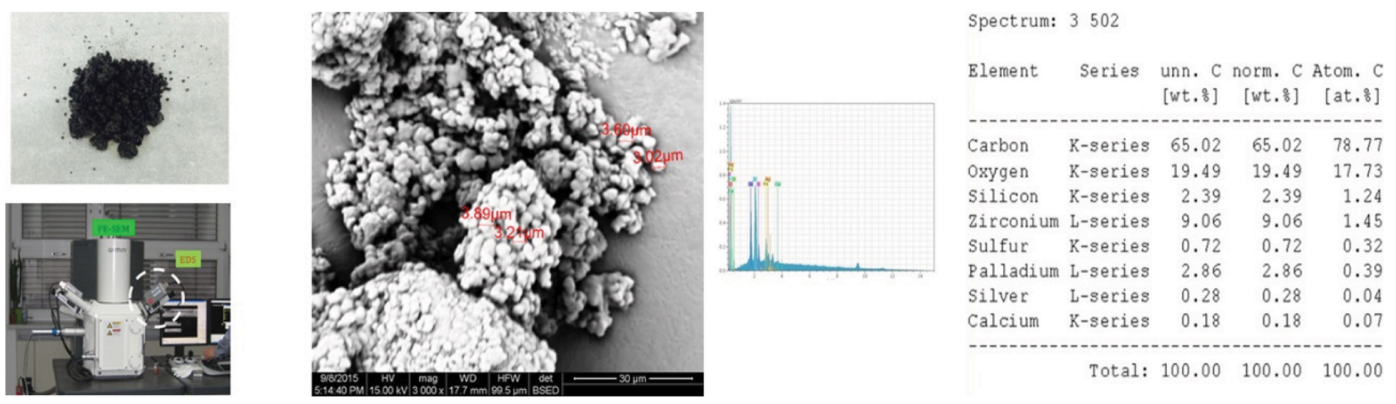

(B)
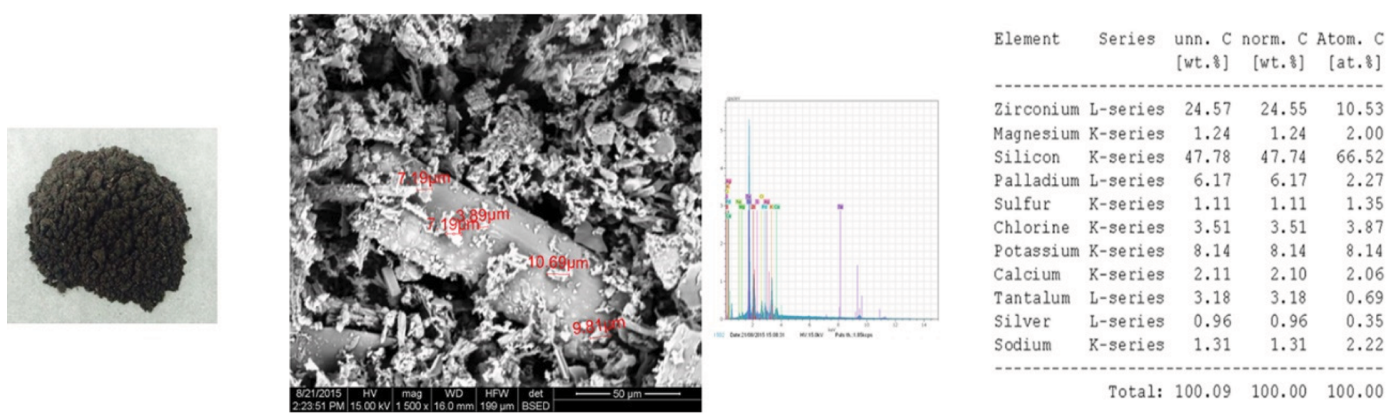

(C)
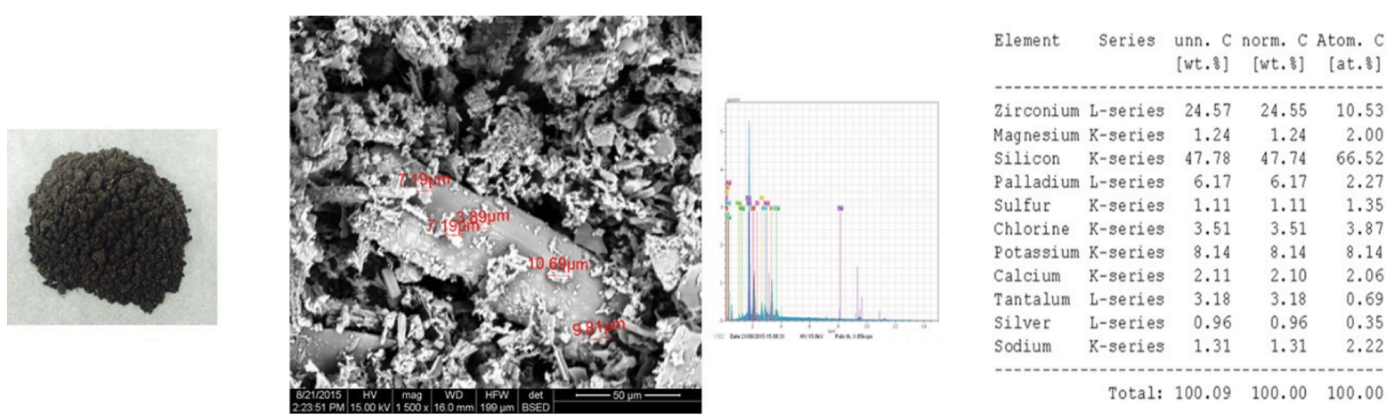

(D)
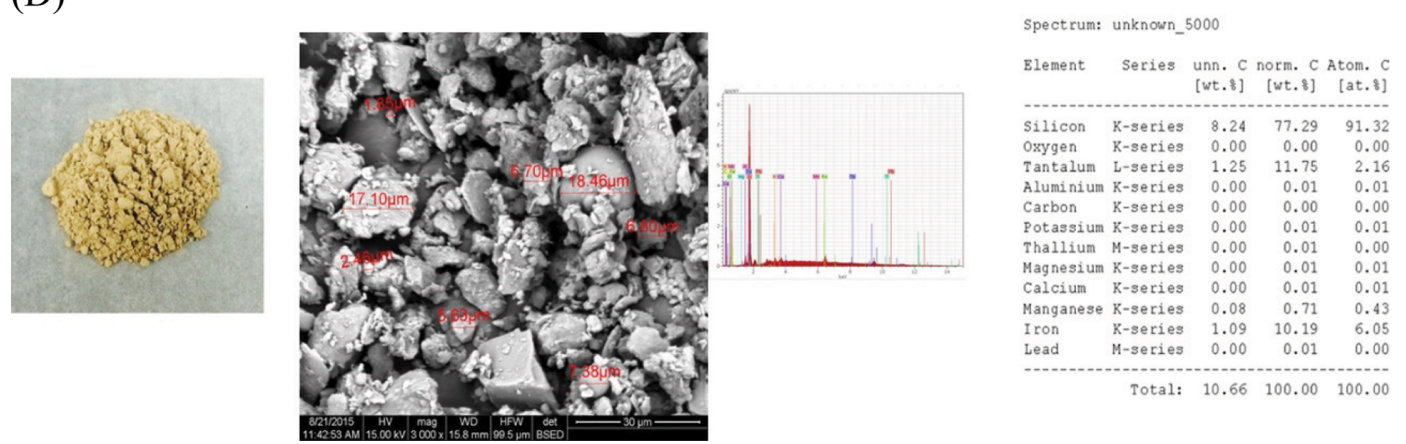

Fig. 1. Physiochemical properties determined using SEM and energy dispersive X-ray spectroscopic analysis of air pollutant particles. (A) DEP, (B) NOC ashes, (C) SOC ashes, and (D) YSD. SEM, scanning electron microscopy; DEP, diesel exhaust particles; YSD, yellow sand dust; NOC, natural organic combustion; SOC, synthetic organic combustion.

- SOC: The SOC particle size was $\geq 4.0 \mu \mathrm{m}$. The synthetic organic matter used in this study did not burn by itself and produce thick, black smoke. Furthermore, it was completely withered by heat with poor light. Most of the SOC ashes were brown black and liberal. The chemical elements detected in the SOC were black carbon, aluminum, silicon, zirconium, and palladium. Black carbon was present at the highest level in the SOC ashes, followed by zirconium, pal- 
ladium, silicon, aluminum, and sulfur, in order of relative ratio. The SOC process was likely incomplete without a forced oxygen supply and was variable. Yang et al. (20) reported that the average PM2.5/TPM ratio emitted from a municipal solid waste incinerator was 0.93 , and the major chemical species detected in PM2.5 were organic carbon, chloride ions, ammonium ions, elemental carbon, and silicon, while the minor species were sulfate ions, potassium ions, sodium, potassium, nitrate, aluminum, calcium ions, zinc, calcium, copper, iron, lead, and magnesium. Fujimori et al. (21) reported that the chemical determinants of the generation of aromatic- $\mathrm{Cl}$, such as polychlorinated biphenyls (PCBs) and chlorobenzenes, in fly ashes from municipal solid waste incineration were the precise ratios of copper, iron, lead, and zinc chlorides and oxides.

- YSD: The YSD particles also had a wide size range, from 1.86 to $18.46 \mu \mathrm{m}$. YSD is not a combustion product, but it is blown over to Korea from China on the westerlies. The YSD particles were yellow and spherical. Silicon was the most abundant element in YSD, followed by tantalum, iron, manganese, aluminum, potassium, magnesium, and calcium, in that order. Ma et al. (22) investigated the physi- cochemical properties of YSD using a multiple analysis method and reported the major components to be aluminum silica, silicon dioxide, and calcium carbonate, with organic compounds and inorganic nitrates coated on the particle surfaces. Noh et al. (23) estimated the mass concentration of YSD based on the weight percentage (38 77\%) of the mineral quartz. Compared to other particles, YSD was mainly composed of inorganic elements, and organic substances, such as fungi and bacteria, were also detected.

Mutagenicity. Fig. 2 shows the change in the number of revertant colonies following treatment of the $S$. typhimurium TA 98 strain with various concentrations of APPs. The characteristics of the TA 98 strain are useful for detecting a frame-shift type mutation. Comparing the relative mutagenicity of the four samples in the TA 98 strain showed that DEPs dose-dependently increased the revertant colony number at low concentrations. Contrastingly, the revertant colony number decreased at higher concentrations, specifically greater than $100 \mu \mathrm{g} /$ plate.

Based on these results, we determined that DEPs at a high concentration were highly toxic in the TA 98 strain culture
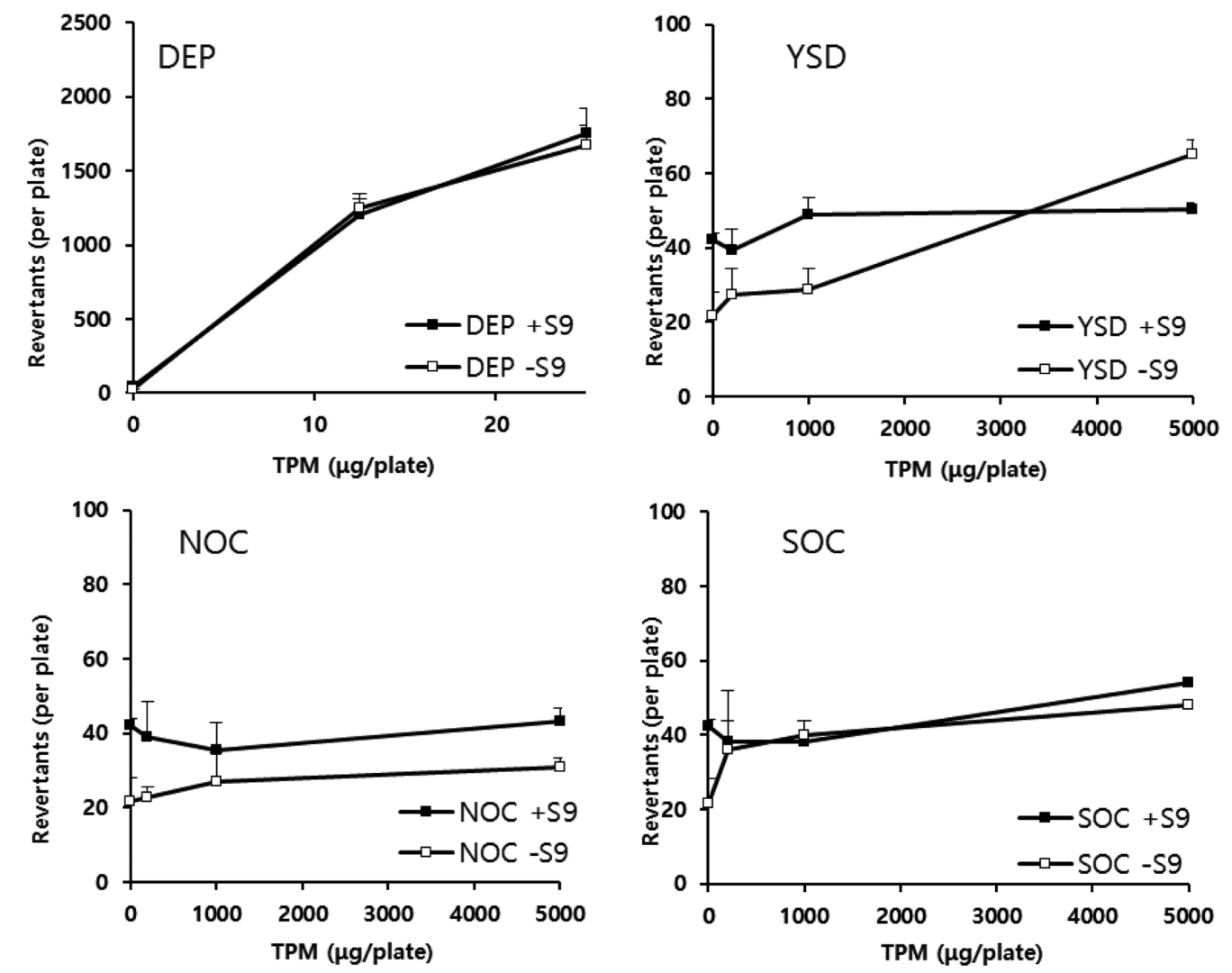

Fig. 2. Change in revertant colony numbers of DEPs, NOC ashes, SOC ashes, and YSD. Salmonella typhimurium TA 98 strains with and without S-9 metabolic activation systems were used to examine the potential of the air pollutant particles to induce mutation. The number of revertant colonies in DMSO-treated $(0.1 \mathrm{~mL} /$ plate), $2 \mathrm{AA}$-treated $(0.5 \mu \mathrm{g} /$ plate), and 4NQO-treated $(0.5 \mu \mathrm{g} / \mathrm{plate}) \mathrm{groups}$ was $34 \pm 5,579 \pm 22$, and $547 \pm 24$, respectively. DEP, diesel exhaust particles; NOC, natural organic combustion; SOC, synthetic organic combustion; YSD, yellow sand dust; DMSO, dimethyl sulfoxide; TMP, total particulate matter. 
Table 1. Mutagenicity of total particulate matter (TPM) from four kinds of air pollutant particles

\begin{tabular}{lcc}
\hline \hline & \multicolumn{2}{c}{ Salmonella typhimurium tester TA 98 } \\
\hline Sample & $\begin{array}{c}\text { Specific activity with S9 } \\
\text { (Revertants/mg) }\end{array}$ & $\begin{array}{c}\text { Specific activity without S9 } \\
\text { (Revertants/mg) }\end{array}$ \\
\hline DEP & $71,347 \pm 2,183$ & $66,289 \pm 4,872$ \\
YSD & Nontoxic up to $5,000 \mu \mathrm{g} /$ plate \\
NOC ash & Nontoxic up to $5,000 \mu \mathrm{g} /$ plate \\
SOC ash & Nontoxic up to $5,000 \mu \mathrm{g} /$ plate \\
\hline & Salmonella typhimurium tester TA 100 \\
\hline Sample & $\begin{array}{r}\text { Specific activity with S9 } \\
\text { (Revertants/mg) }\end{array}$ & Specific activity without S9 \\
& (Revertants/mg) \\
\hline DEP & $20,941 \pm 1,119$ & $23,739 \pm 2,217$ \\
YSD & Nontoxic up to $5,000 \mu \mathrm{g} /$ plate \\
NOC ash & \multicolumn{2}{c}{ Nontoxic up to $5,000 \mu \mathrm{g} /$ plate } \\
SOC ash & \multicolumn{2}{c}{ Nontoxic up to $5,000 \mu \mathrm{g} /$ plate }
\end{tabular}

DEP, diesel exhaust particles; YSD, yellow sand dust; NOC, natural organic combustion; SOC, synthetic organic combustion. system and, therefore, could not stimulate its growth (data not shown). NOC, SOC, and YSD particles did not promote the TA 98 strain growth even at high TPM concentrations. When the revertant colony number was measured following treatment with $1 \mathrm{mg}$ TPM, the values for DEPs were $71,347 \pm 2,183$ and $66,289 \pm 4,872$ with and without the S-9 mix, respectively (Table 1). Consequently, DEPs and its metabolites exhibited a high mutagenic activity. However, none of the NOC, SOC, and YSD particles and their hepatic metabolites exhibited any mutagenic activity in the TA 98 strain culture system.

The changes in the number of revertant colonies at different concentrations of the four kinds of APPs are shown in Fig. 3. The characteristics of the TA 100 strain are useful for identifying base-pair substitution type mutations. In the TA 100 culture system, similar to the TA 98 strain, DEPs dose-dependently elevated the revertant colony number at low concentrations, and this number decreased at concentrations $>100 \mu \mathrm{g} /$ plate of DEPs.
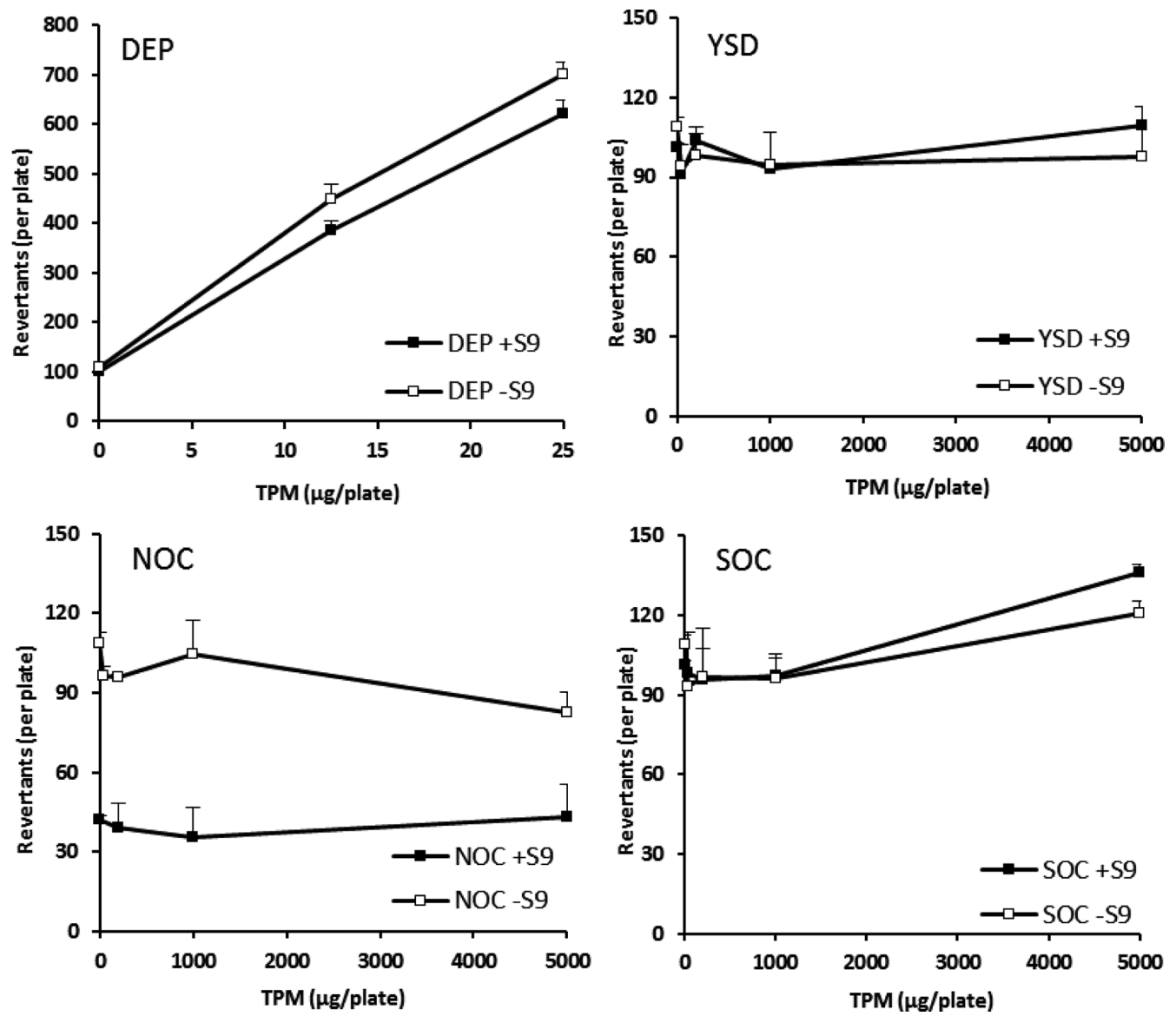

Fig. 3. Change in revertant colony numbers of DEPs, NOC ashes, SOC ashes, and YSD. Salmonella typhimurium TA 100 strain with and without S-9 metabolic activation system was used to examine the potential of the air pollutant particles to induce mutation. The number of revertant colonies in DMSO-treated $(0.1 \mathrm{~mL} /$ plate), 2 AA-treated $(0.5 \mu \mathrm{g} / \mathrm{plate})$, and SA-treated $(1.0 \mu \mathrm{g} / \mathrm{plate})$ groups was $123 \pm 17$, $1,745 \pm 123$, and 1,342 \pm 98 , respectively. DEP, diesel exhaust particles; NOC, natural organic combustion; SOC, synthetic organic combustion; YSD, yellow sand dust; DMSO, dimethyl sulfoxide. 


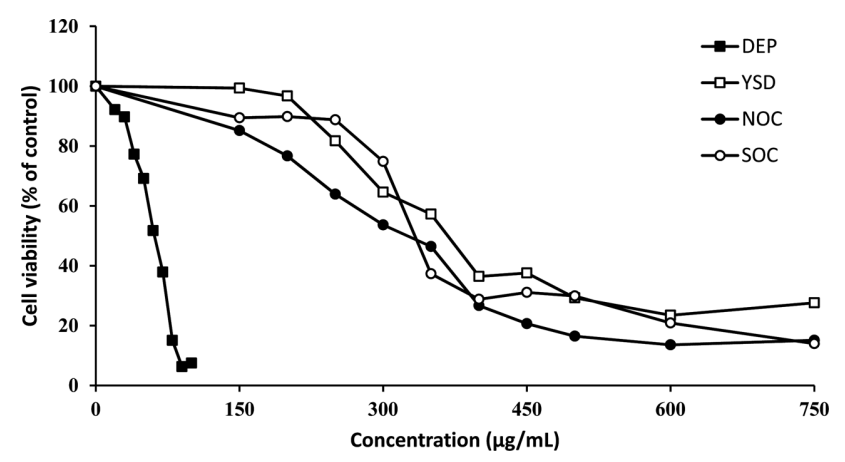

Fig. 4. Cytotoxicity of TPM of four kinds of air pollutant particles, DEPs, NOC ashes, SOC ashes, and YSD. CHO cells were treated with various concentrations of TPM $(\mu \mathrm{g} / \mathrm{mL})$ for $24 \mathrm{hr}$. Data are expressed mean \pm SD. TMP, total particulate matter; DEP, diesel exhaust particles; NOC, natural organic combustion; SOC, synthetic organic combustion; YSD, yellow sand dust; SD, standard deviation.

However, NOC, SOC, and YSD particles in the TA 100 strain culture system did not increase the growth even at high doses, similar to that observed for the TA 98 strain. When the revertant colony number was measured on the basis of $1 \mathrm{mg}$ TPM, the values for DEPs were 20,941 \pm 61 and $23,739 \pm 7$ with and without the S-9 mix, respectively. Consequently, both DEPs and its metabolites had a high mutagenic effect. However, none the NOC, SOC, and YSD particles and their hepatic metabolites showed any mutagenic activity in the TA 100 strain culture system.

Cytotoxicity. Fig. 4 shows the change in cell viability following treatment of the $\mathrm{CHO}-\mathrm{K} 1$ cell culture system with various concentrations of the four kinds of APPs. The TPM fractions of DEPs, NOC ashes, SOC ashes, and YSD were applied to $\mathrm{CHO}$ cells at a range associated with concentration-dependent responses. The viability of treated cell groups was calculated relative to that of the normal cells, which was considered $100 \%$. DEPs decreased the cell viability precipitously at a low concentration, but NOC, SOC, and YSD particles decreased the viability gradually. Table 2 presents the change in cell viability following treatment with various concentrations and the $\mathrm{EC}_{50}$ values that were

Table 2. Effective concentration $\left(E C_{50}\right)$ values and relative cytotoxicity of four kinds of air pollutant particles

\begin{tabular}{lcc}
\hline \hline Samples & $\begin{array}{c}\text { Cytotoxicity } \\
\left(\mathrm{EC}_{50}, \mu \mathrm{g} / \mathrm{mL}\right)\end{array}$ & $\begin{array}{c}\text { Relative cytotoxicity } \\
(\% \text { of DEP })\end{array}$ \\
\hline DEP & $58.2 \pm 3.0$ & 100 \\
YSD & $451.3 \pm 36.6$ & 12.9 \\
NOC ash & $339.0 \pm 8.6$ & 17.2 \\
SOC ash & $327.4 \pm 33.3$ & 17.8 \\
\hline
\end{tabular}

DEP, diesel exhaust particles; YSD, yellow sand dust; NOC, natural organic combustion; SOC, synthetic organic combustion. calculated to compare the relative cytotoxicity of the four FPs.

All four FP types showed dose-dependent cytotoxicity. The $\mathrm{EC}_{50}$ values for DEPs, NOC ashes, SOC ashes, and YSD particles were $58.2 \pm 3.0,339.0 \pm 8.6,327.4 \pm 33.3$, and $451.3 \pm 36.6$, respectively. Therefore, we concluded that DEP exhibited the highest cytotoxicity of the four FP types, while NOC and SOC showed similar levels of cytotoxicity, which did not differ significantly. Furthermore, YSD showed the weakest cytotoxicity of all four FPs.

\section{DISCUSSION}

APPs are a complex mixture of organic and inorganic compounds and include a number of toxic compounds such as metals and PAHs. Combustion processes emit large quantities of particles into the atmosphere. Particles formed in combustion systems are classified into two categories. The first category, referred to as ash, comprises particles derived from noncombustible constituents. The second category consists of carbonaceous particles that are formed by pyrolysis of fuel molecules such as diesel, coal, and wood.

The purpose of this study was to investigate the physical characteristics and analyze the chemical elements in four kinds of APPs (DEPs, NOC ash, SOC ash, and YSD). In addition, we compared their in vitro toxicological activity, including mutagenicity and cell toxicity, to evaluate their relative contribution to human health effects.

Many previous studies have reported that the in vitro biological activity of ambient air particles showed different responses according to not only particle size, but also a different type of chemical element (24). The indirect- and direct-acting mutagenicity of DEPs, NOC ash, SOC ash, and YSD were determined using the Ames test on S. typhimurium TA 98 and 100 strains. DEP showed the highest specific activity in both strains, and its indirect mutagenicity was higher than its direct-acting mutagenicity in the TA 98 strain. However, in the TA 100 strain, the indirect mutagenicity was lower than the direct-acting mutagenicity. The aromatic amines, PAHs, and heterocyclic amines, in DEPs are known to induce mutations and carcinogenesis $(25,26)$.

Cytotoxicity was found to be affected by the constituent, size, and exposure time of the test chemicals. The cytotoxicity results indicated the concentration-dependent effects of DEPs, NOC ash, SOC ash, and YSD.

Based on the $\mathrm{EC}_{50}$ values of DEP, NOC, SOC, and YSD, we concluded that DEP showed the highest cytotoxicity of the four FP while NOC and SOC exhibited comparable levels of cytotoxicity with no significant difference. Furthermore, YSD showed the weakest cytotoxicity of all four FPs. Numerous previous studies have reported that higher content of metals or PAHs are associated with greater quantities of ROS produced in the particle-exposed cells $(27,28)$. 
Therefore, the high content of metals and PAHs in DEP could have mediated its acute cell cytotoxicity.

\section{ACKNOWLEDGMENTS}

This research was supported by the Research Program to Solve Social Issues of the National Research Foundation of Korea (NRF), which was funded by the ministry of Science, ICT \& Future Planning (NRF-2015M3C8A5060129).

Received May 7, 2017; Revised July 25, 2017; Accepted July 31,2017

\section{REFERENCES}

1. Farina, F., Sancini, G., Mantecca, P., Gallinotti, D., Camatini, M. and Palestini, P. (2011) The acute toxic effects of particulate matter in mouse lung are related to size and season of collection. Toxicol. Lett., 202, 209-217.

2. Sancini, G., Farina, F., Battaglia, C., Cifola, I., Mangano, E., Mantecca, P., Camatini, M. and Palestini, P. (2014) Health risk assessment for air pollutants: alterations in lung and cardiac gene expression in mice exposed to Milano winter fine particulate matter (PM 2.5). PLOS ONE, 9, e109685.

3. Jassal, M.S. (2015) Pediatric asthma and ambient pollutant levels in industrializing nations. Int. Health, 7, 7-15.

4. Adams, K., Greenbaum, D.S., Shaikh, R., van Erp, A.M. and Russel, A.G. (2015) Particulate matter components, sources, and health: Systematic approaches to testing effects. J. Air Waste Manag. Assoc., 65, 544-558.

5. Luanpitpong, S., Chen, M., Knuckles, T., Wen, S., Luo, J., Ellis, E., Hendryx, M. and Rojanasakul, Y. (2014) Appalachian mountaintop mining particulate matter induces neoplastic transformation of human bronchial epithelial cells and promotes tumor formation. Environ. Sci. Technol., 48, 1291212919.

6. Gong, J., Zhu, T., Kipen, H., Rich, D.Q., Huang, W., Lin, W.T., Hu, M. and Zhang, J.J. (2015) Urinary polycyclic aromatic hydrocarbon metabolites as biomarkers of exposure to traffic-emitted pollutants. Environ. Int., 85, 104-110.

7. Dumax-Vorzet, A.F., Tate, M., Walmsley, R., Elder, R.H. and Povey, A.C. (2015) Cytotoxicity and genotoxicity of urban particulate matter in mammalian cells. Mutagenesis, 30, 621633.

8. Prange, J.A., Gaus, C., Weber, R., Papke, O. and Muller, J.F. (2003) Assessing forest fire as a potential PCDD/F source in Queensland, Australia. Environ. Sci. Technol., 37, 4325-4329.

9. Simon, E., Choi, S.D. and Park, M.K. (2016) Understanding the fate of polycyclic aromatic hydrocarbons at a forest fire site using a conceptual model based on field monitoring. $J$. Hazard. Mater., 317, 632-639.

10. Noma, Y., Yamamoto, T., Giraud, R. and Sakai, S. (2006) Behavior of PCNs, PCDDs, PCDFs, and dioxin-like PCBs in the thermal destruction of wastes containing PCNs. Chemosphere, 62, 1183-1195.

11. Yamada, P., Hatta, T., Du, M., Wakimizu, K., Han, J., Maki, T. and Isoda, H. (2012) Inflammatory and degranulation effect of yellow sand on RBL-2H3 cells in relation to chemical and biological constituents. Ecotoxicol. Environ. Saf., 84, 9-17.

12. Hayakawa, K. (2016) Environmental behaviors and toxicities of polycyclic aromatic hydrocarbons and nitropolycyclic aromatic hydrocarbons. Chem. Pharm. Bull., 64, 83-94.

13. Nadal, M., Marques, M., Mari, M. and Domingo, J.L. (2015) Climate change and environmental concentrations of POPs: A review. Environ. Res., 143, 177-185.

14. Sagai, M., Saito, H., Ichinose, T., Kodama, M. and Mori, Y. (1993) Biological effects of diesel exhaust particles. I. In vitro production of superoxide and in vivo toxicity in mouse. Free Radic. Biol. Med., 14, 37-47.

15. Maron, D.M. and Ames, B.N. (1983) Revised methods for the Salmonella mutagenicity test. Mutat. Res., 113, 173-215

16. Borenfreund, E. and Puerner, J.A. (1985) Toxicity determined in vitro by morphological alterations and neutral red absorption. Toxicol. Lett., 24, 119-124.

17. Surawski, N.C., Miljevic, B., Avoko, G.A., Elbaqir, S., Stevanovic, S., Fairfull-Smith, K.E., Bottle, S.E. and Ristovski, Z.D. (2011) Physicochemical characterization of particulate emissions from a compression ignition engine: the influence of biodiesel feedstock. Environ. Sci. Technol., 45, 1033710343.

18. Faustini, A., Alessandrini, E.R., Pey, J., Perez, N., Samoli, E., Querol, X., Cadum, E., Perrino, C., Ostro, B., Ranzi, A., Sunyer, J., Stafoggia, M. and Forastiere, F. (2015) Short-term effects of particulate matter on mortality during forest fires in Southern Europe: results of the MED-PARTICLES project. Occup. Environ. Med., 72, 323-329.

19. Naeher, L.P., Brauer, M., Lipsett, M., Zelikoff, J.T., Simpson, C.D., Koeniq, J.Q. and Smith, K.R. (2007) Woodsmoke health effects: a review. Inhal. Toxicol., 19, 67-106.

20. Yang, H.H., Luo, S.W., Lee, K.T., Wu, J.Y., Chang, C.W. and Chu, P.F. (2016) Fine particulate speciation profile and emission factor of municipal solid waste incinerator established by dilution sampling method. J. Air Waste Manag. Assoc., 66, 807-814.

21. Fujimori, T., Tanino, Y. and Takaoka, M. (2014) Coexistence of $\mathrm{Cu}, \mathrm{Fe}, \mathrm{Pb}$, and $\mathrm{Zn}$ oxides and chlorides as a determinant of chlorinated aromatics generation in municipal solid waste incinerator fly ash. Environ. Sci. Technol., 48, 85-92.

22. Ma, Q., Liu, Y., Liu, C., Ma, J. and He, H. (2012) A case study of Asian dust storm particles: chemical composition, reactivity to $\mathrm{SO} 2$ and hygroscopic properties. J. Environ. Sci. (China), 24, 62-71.

23. Noh, Y., Muller, D., Shin, S.K., Shin, D. and Kim, Y.J. (2016) Vertically-resolved profiles of mass concentrations and particle backscatte coefficients of Asian dust plumes derived from lidar observations of silicon dioxide. Chemosphere, 143, 2431.

24. Jalava, P.I., Raimo, O.S., Kati, N., Arto, S.P., Mikko, S.H., Jarkko, T., Anna, F., Risto, H., Jorma, J. and Maija-Riitta, H. (2010) Effect of combustion condition on cytotoxic and inflammatory activity of residential wood combustion particles. Atmos. Environ., 44, 1691-1698.

25. Hashimoto, A.H., Amanuma, K., Hiyoshi, K., Sugawara, Y., Goto, S., Yanagisawa, R., Takano, H., Masumura, K., Nohmi, T. and Aoki, Y. (2007) Mutations in the lungs of gpt delta transgenic mice following inhalation of diesel exhaust. Environ. Mol. Mutagen., 48, 682-693. 
26. Rivedal, E., Myhre, O., Sanner, T. and Eide, I. (2003) Supplemental role of the Ames mutation assay and gap junction intercellular communication in studies of possible carcinogenic compounds from diesel exhaust particles. Arch. Toxicol., 77, 533-542.

27. Gaffney, J.S. and Nancy, A.M. (2009) The impacts of combustion emissions on air quality and climate - From coal to biofuels and beyond. Atmos. Environ., 43, 23-36.

28. Manzo, N.D., Slade, R., Richards, J.H., McGee, J.K., Martin, L.D. and Dye, J.A. (2010) Susceptibility of inflamed alveolar and airway epithelial cells to injury induced by diesel exhaust particles of varying organic carbon content. J. Toxicol. Environ. Health Part A, 73, 565-580. 